\title{
Las comisiones de diversidad funcional en el 15M español: poner el cuerpo en el espacio público
}

\author{
Míriam ARENAS CONEJO \\ Universitat Oberta de Catalunya \\ miriam.arenas.bcn@gmail.com
}

\author{
Asun Pié BALAgUeR \\ Universitat Oberta de Catalunya \\ apieb@uoc.edu
}

Recibido: 06-06-2013

Aceptado con modificaciones: 15-01-2014

Aceptado finalmente: 26-02-2014

\begin{abstract}
Resumen
El objetivo del presente texto es analizar algunas de las implicaciones que tuvieron las comisiones de diversidad funcional, creadas en dos ciudades españolas durante las acampadas del movimiento $15 \mathrm{M}$, en el año 2011. Para ello, en primer lugar, situamos dichas comisiones en el marco de la evolución histórica de la militancia en torno a la discapacidad en España. En segundo lugar, describimos las características de las comisiones en el marco de las acampadas del $15 \mathrm{M}$, a partir de materiales que publicaron en Internet junto con la valoración de algunas personas participantes. A partir de esta contextualización, entramos a analizar la que destacamos como la aportación más relevante de las comisiones. Se trata de la experiencia de "poner el cuerpo en la plaza", una forma de política encarnada en el espacio público. Ésta permitió abrir un debate sobre las lógicas de exclusión/inclusión ciudadanas, recuperando a su vez la conciencia de que la precariedad y la vulnerabilidad son una realidad común a todo ser humano. Concluimos así, que las comisiones de diversidad funcional supusieron un momento relevante para la militancia de la discapacidad y para el 15M, al estar utilizando el cuerpo como una herramienta de liberación para cuestionar la misma definición de lo humano.
\end{abstract}

Palabras clave discapacidad, diversidad funcional, 15M, movimientos sociales, vulnerabilidad, militancia, precariado

\section{Committees of functional diversity in the Spanish 15M: putting the body in the public space}

\begin{abstract}
This article aims to analyze some of the implications of the committees of functional diversity created in two Spanish cities during the 15M camps of 2011. Firstly, we situate them in the context of the historical evolution of disability activisms in Spain. Secondly, we describe the main traits of such committees within the $15 \mathrm{M}$, based on their published materials on the Internet along with the assessments of some participants. Once contextualized, we analyze what we have considered the main contribution of the committees. It is the experience of "putting the body in the square", a form of embodied politics performed at the public space. This opened a debate on the logics of exclusion /
\end{abstract}


inclusion within citizenship, and in turn it got back the awareness that precariousness and vulnerability are common traits of every human being. Therefore, we conclude that the committees of functional diversity represented a significant moment for both the disability activism and the $15 \mathrm{M}$ movement, with their use of the body as a liberatory tool to question the very definition of the human

Key words: disability, functional diversity, 15M, social movements, vulnerability, activism, precariat.

\section{Referencia normalizada}

Arenas Conejo, M. y Pié Balaguer, A.. (2014). "Las comisiones de diversidad funcional en el 15M español: poner el cuerpo en el espacio público”. Política y Sociedad, Vol.51 Núm. 1 227-245

Sumario: Introducción. 1.Orígenes de la tradición militante de la discapacidad. 2.La llegada del modelo social y la radicalización de la militancia. 3.Las comisiones de diversidad funcional. 4.La común vulnerabilidad. 5.El cuerpo y la plaza. 6.Conclusiones. Bibliografía 
Ha sido una de las mejores experiencias vividas, a nivel de aprendizaje y de trabajo común, en relación con la comisión y con el resto del movimiento $15 M^{1}$.

\section{Introducción}

La noción de discapacidad es una construcción social que ha ido configurándose con la adopción y acumulación de nombres y definiciones, por influencia de distintas tradiciones culturales, religiosas, científicas y políticas. Estas categorizaciones son un campo de contestación entre los diversos agentes implicados, que da cuenta de las importantes implicaciones sociales, económicas y políticas asociadas al hecho de asumir una definición u otra (Mitra, 2006). El siglo $\mathrm{XX}$ ha supuesto un sinfín de acciones, del propio colectivo, para descategorizarse como sujetos receptores de prestaciones caritativas, benéficas y como sujetos definidos por sus aspectos negativos. No obstante, esta politización es un fenómeno bastante reciente en el caso español, donde la tradición militante en cuestiones de discapacidad es escasa (Planella y Pié, 2012).

En este texto presentamos un estudio sobre la situación actual de la militancia de la discapacidad en España, a partir de una aproximación a las comisiones de diversidad funcional que se crearon en las acampadas del 15M en Madrid y Barcelona (2011). En primer lugar, hacemos un recorrido sobre las formas de activismo que ha habido en España en torno a la cuestión de la discapacidad. Como veremos, tras el modelo asistencialista surgido durante el franquismo, en el periodo de transición democrática de los setenta se abrió un periodo de intensa movilización que logró notables avances, no obstante, todavía anclados en el modelo médico. Será a partir de los noventa cuando se empiecen a dar los primeros pasos hacia el modelo social y de derechos humanos, que acabará generando una nueva forma de militancia. Este tipo de activismo encontrará importantes paralelismos con algunas de las ideas y modelos organizativos del 15M en el 2011, dando lugar a las comisiones de diversidad funcional. Tras delinear algunas de las características básicas que caracterizaron a estas comisiones entramos a analizar sus implicaciones, tanto en relación con las nuevas maneras de entender la política en torno a la discapacidad, como su influencia en el modelo político, económico y social que se estaba ensayando en el 15M. Observamos cómo las comisiones de diversidad funcional, en el contexto del 15M, muestran dos elementos de participación política emergentes. En primer lugar la centralidad de las nociones de vulnerabilidad y precariedad en las movilizaciones y, en segundo lugar, el uso del cuerpo como herramienta política y arma de consenso.

\footnotetext{
${ }^{1}$ Afirmación de una participante de la comisión de diversidad funcional de la acampada de Barcelona.
} 


\section{Orígenes de la tradición militante de la discapacidad}

Sobre las personas con discapacidad pesa una larga historia de discursos negativos y de subordinación, al haberse interpretado su realidad tradicionalmente o bien como un "castigo divino" (modelo de la prescindencia), o como un problema individual a ser corregido mediante la intervención médica (modelo médicorehabilitador). El modelo médico, bajo la bandera de la mejora de las condiciones de vida de las personas con discapacidad, desarrolló procedimientos sanitarios aunque colocó a los sujetos en el lugar de objetos sobre los que intervenir, desde parámetros científicos, cuantitativos y supuestamente universales de "normalidad" y "salud" (Mitra, 2006; Ferreira, 2010). En España, los primeros intentos sociopolíticos para pasar a un modelo médico de la discapacidad no se producen hasta el primer tercio del siglo XX. Hacia 1940, en plena dictadura franquista, se crean las primeras asociaciones de familiares de personas con discapacidad que conjugaban la reivindicación de derechos (de protección económica, educativa, sanitaria, ocupacional y asistencial) con la prestación de servicios no cubiertos por el Estado (Díaz, 2008). Todo ello con una gran influencia de la Iglesia Católica (Maraña y Lobato, 2003). Este movimiento asociativo tomó fuerza en los años sesenta, desplegando una red de recursos y prestaciones paralelos al del resto de la ciudadanía, mediante un complejo sistema de financiación pública con gestión privada (Fierro, 1984; Díaz, 2008).

Durante la transición democrática observamos un intenso periodo de reivindicaciones que responden a la necesidad vital de presionar al Gobierno para solucionar la poca cobertura legislativa del colectivo. Se logró que finalmente, en la Constitución Española de 1978, se incluyera una referencia explícita a las personas con discapacidad en un marco de igualdad de oportunidades, que llegaba "con un retraso más que notable respecto al resto de Europa" (Maraña y Lobato, 2003: 260). En realidad, fue a partir de 1974 que empezó la gestación de lo que más adelante sería la "la rebelión de los cojos" (Pérez, 1992) que siguió con varias medidas de movilización y presión política en los años sucesivos. Durante éstos se crearon un gran número de entidades asociativas, "un germen de cultura de la discapacidad y un deseo de cambio radical en la orientación de las políticas sociales", pero "en su contra operaban una reciente crisis económica mundial, deprimentes índices de desempleo y todo el sistema de administración del Estado transitando desde un rígido centralismo hacia estructuras descentralizadas en el marco de las

${ }^{2}$ El 4 de noviembre de 1977 se tomaron por asalto los locales del SEREM en la calle Grassot de Barcelona, como un baluarte de presión al Gobierno central. Durante los primeros días del encierro, decidieron en una asamblea llevar a cabo unas acciones muy puntuales para llamar la atención de los ciudadanos, como fueron encadenamientos en las Ramblas o la interrupción de una función en el Gran Teatre del Liceu lanzando octavillas al público (Pérez, 1992). 
Autonomías" (Maraña y Lobato, 2003: 260-261). La limitación de las dotaciones presupuestarias por el contexto económico, acabaron reforzando "las propuestas neoliberales de contención de gasto y provisión indirecta de los servicios públicos" (Jiménez y Huete, 2010: 143). A esto se sumaba un cuerpo funcionarial que, o bien no tenía referentes claros en materia de servicios sociales para personas con discapacidad, o bien estaba "atado por la coexistencia de diversas formas de acción social heredadas del régimen anterior" (Maraña y Lobato, 2003: 261).

Por lo tanto, hasta la década de los $80^{3}$, el movimiento asociativo de la discapacidad en España, siguió mayoritariamente bajo el paradigma del modelo médico, aunque ya existieron experiencias de movilización que sentaron las bases para lo que llegaría dos décadas más tarde. Pero la existencia de un sistema de dependencia mutua con la administración, fue erosionando la vertiente reivindicativa y política que en su origen habían tenido estas asociaciones, acercándose cada vez más a modelos de gestión empresarial, y a las que los asociados se vinculaban más como clientes o consumidores que por vocación política (Díaz, 2008).

\section{La llegada del modelo social y la radicalización de la militancia}

Desde la década de los 70, impulsado por el Movimiento de Vida Independiente, venía desarrollándose en Estados Unidos y algunos países del norte de Europa el modelo social de la discapacidad (Barnes et al., 1999). A diferencia del modelo médico, éste sostiene que las diferencias biológicas o funcionales no explican por sí mismas la discriminación o la exclusión social, sino que la discapacidad es el resultado de unas estructuras sociales opresivas, excluyentes y marginalizadoras (Ferreira, 2010). Desde esta perspectiva, ya no se buscan soluciones médicas individuales sino que el activismo se orienta a reivindicar políticas públicas que eliminen estas barreras (Palacios y Bariffi, 2007).

Este nuevo modelo no empieza a llegar a España hasta la década de los 90, generando una recuperación en la dimensión reivindicativa a través de nuevas formas de participación. En un ámbito más formal, en el año 1997 se crea el Comité Español de Representantes de Personas con Discapacidad (CERMI): una plataforma unitaria integrada por asociaciones de todos los tipos de discapacidad, cuya misión originaria fue generar una acción política representativa en defensa de los derechos

${ }^{3}$ Durante la década de los años 80 también se produjo un importante despliegue normativo del que puede destacarse la LISMI (Ley de Integración Social del Minusválido, 1982), garantizando derechos en materia de prestaciones económicas y servicios sociales (Toboso, 2013), aunque más orientado a la protección de la persona con discapacidad que a eliminar las barreras que dificultan su participación y el disfrute de sus derechos ciudadanos (Jiménez y Huete, 2010). 
e intereses de las personas con discapacidad, tanto colectiva como individualmente. Actuando a modo de lobby, su trabajo se ha centrado principalmente en el ámbito de las políticas sociales y de la legislación (Díaz, 2008).

La primera ley que incorpora elementos del modelo social no llegará hasta el año 2003, con la aprobación de la LIONDAU (Ley 51/2003 de Igualdad de Oportunidades, no discriminación y Accesibilidad Universal de las personas con discapacidad). En esta ley, por primera vez, se pone el acento en la responsabilidad del medio social respecto a la discriminación y la falta de igualdad de oportunidades (Centeno, 2012). Un giro que se ha culminado con la ratificación de España, en el año 2007, de la Convención Internacional sobre los Derechos de las Personas con Discapacidad de las Naciones Unidas y la armonización y refundición, en el año 2013, de toda la legislación previa sobre discapacidad en la Ley General de derechos de las personas con discapacidad y de su inclusión social ${ }^{4}$.

La incorporación del modelo social y del lenguaje de los derechos humanos también ha ido dando lugar en la última década a nuevos posicionamientos militantes, más críticos y radicales ante la administración y la sociedad. Así, han ido surgiendo nuevas asociaciones que siguen un modelo organizativo similar al desarrollado en otros países: autogestión, ayuda mutua y el empoderamiento de las personas con discapacidad (Barnes et al., 1999).

Ya no se agrupan tanto en torno a un diagnóstico médico o un tipo de deficiencia, sino más bien alrededor de un tipo concreto de necesidad, reivindicación, o rechazo de discriminación. En este movimiento además, crecen con fuerza las organizaciones e iniciativas de auto-representación, con gran protagonismo de la reivindicación por encima de la gestión de servicios y en el que el control lo toman las propias personas con discapacidad, en vez de las familias (Jiménez y Huete, 2010: 149).

En el impulso del modelo social, cabe destacar la creación del Foro de Vida Independiente y Divertad (FVID) en el año 2001: una comunidad virtual de personas con discapacidad de habla hispana, sin ningún tipo de base jurídica ni estructura institucional, nacido ante la insatisfacción "con las funciones prestacionales que suelen adoptar como prioritarias las entidades, sin cuestionarse los resultados sobre la autonomía e integración social de las personas" (Díaz, 2008: 192). El FVID se propone como objetivo dar una mayor visibilidad a las personas con discapacidad y luchar sin intermediarios, mediante la reflexión y la acción, por la integración real desde la autonomía personal y contra todo lo que representen situaciones de discriminación por razón de discapacidad. Esta nueva cultura de la militancia y de la participación política se visibilizó especialmente durante el

\footnotetext{
${ }^{4}$ Real Decreto Legislativo 1/2013, de 29 de noviembre, por el que se aprueba el Texto Refundido de la Ley General de derechos de las personas con discapacidad y de su inclusión social. (BOE, núm. 289, 3-12-2013, Sec. I, pág. 95635-95673).
} 
proceso de elaboración y aprobación de la LEPA (Ley 39/2006 de Promoción de la Autonomía Personal y Atención a las personas en situación de dependencia) ${ }^{5}$. El FVID no centró la discusión en el volumen de recursos y prestaciones sino que llevó a cabo una intensa campaña orientada a corregir los supuestos de base de una ley, que consideraban excesivamente paternalista y patriarcal. Sustentada en el modelo médico y rehabilitador, se denunciaba además que esta nueva ley entraba en contradicción con el paradigma de derechos humanos, ya establecido previamente en España con la LIONDAU (Centeno, 2012: 158).

Pocos años más tarde de su creación, el FVID propone el concepto de Diversidad Funcional ${ }^{6}$ para denominar la discapacidad.

Las mujeres y los hombres con diversidad funcional somos diferentes, desde el punto de vista biofísico, de la mayor parte de la población. Al tener características diferentes, y dadas las condiciones de entorno generadas por la sociedad, nos vemos obligados a realizar las mismas tareas o funciones de una manera diferente, algunas veces a través de terceras personas (Romañach y Lobato, 2005).

Su objetivo no era el de ofrecer una equivalencia al concepto de discapacidad, sino el de crear una nueva mirada no negativa sobre la misma, inspirado en el enfoque de los derechos humanos y con cierta vocación universal. El concepto de diversidad funcional no aboga tanto por una serie de derechos especiales, sino que busca extender la idea de discapacidad y dependencia al mismo fenómeno humano, creando una apertura en los modos de pensarlo como un ser diverso. Sin renunciar a los principios básicos del modelo social, desde el enfoque de derechos humanos, se asume que el hecho de centrarse en medidas o acciones únicamente destinadas a las personas con discapacidad, perpetúa su concepción como grupo minoritario

5 2008-2011. Proyecto CONDEPCIU. “Controversias tecnocientíficas y participación ciudadana entorno a las políticas de atención a la dependencia” (Plan Nacional de I+D: CSO2008-06308-C02-02). Universitat Oberta de Catalunya.

${ }^{6}$ El concepto de Diversidad Funcional fue propuesto por el Foro de Vida Independiente y Divertad en el año 2005. Aunque no es exactamente un sinónimo de "discapacidad", el tipo de utilización más frecuente se asocia a esta equivalencia. Para poder generalizarse, el concepto de diversidad funcional debe incluir distintas variantes. Es decir, en ocasiones la amplitud semántica puede conllevar cierta confusión. Por este motivo, en función del caso se aconseja acotar los tres elementos que abarca: partes del cuerpo que funcionan de otra manera, personas que funcionan de otra manera, personas que funcionan de otra manera y se las discrimina por razón de esta diferencia. "Para este tipo de ajustes que puedan ser necesarios, se proponen los términos 'diferencia orgánica' y 'diferencia funcional', equivalentes a los antiguos 'deficiencia' y ‘discapacidad’ de la clasificación de la OMS de 1980, típicos del modelo rehabilitador, o de nuevo ‘diferencia funcional’ cuando se hable de la ‘deficiencia’ tal y como la concibe el modelo social” (Palacios y Romañach, 2006: 116). 
poseedor de características excepcionales. Se invisibiliza, por lo tanto, que la discapacidad y las disfunciones son rasgos humanos universales (Clements y Read, 2008). La alternativa es superar los modelos basados en la diferencia, defendiendo en cambio, la vulnerabilidad como característica universal e intrínseca del ser humano (Turner, 2006). Esta nueva semántica adoptada por el FVID ha conllevado hasta la actualidad, una controversia sobre los modos de nombrar esta diferencia, generando un giro epistemológico de la discapacidad y potenciando nuevas maneras de entender el activismo político en nuestro país.

A modo de síntesis, observamos dos claros puntos de inflexión histórica en cuanto a presión política se refiere. En primer lugar, el periodo de la transición y la lucha que conllevó la redacción de la LISMI. Del 1975 a 1981 observamos un intenso período de lucha y enfrentamiento político, caracterizado por diversas movilizaciones, encierros y negociaciones. Antes de la llegada de la LISMI (1982) las personas con discapacidad no eran sujetos de derecho sino objetos de asistencia y caridad. Después de este intenso periodo activista se observa una despolitización creciente fruto del logro que supuso el despliegue de servicios y bienes dirigidos a las personas con discapacidad y, especialmente, fruto de la delegación de la función política de las entidades del sector. En la década de los 90 se crea el CERMI con el ánimo de solucionar esta situación de poca representatividad en lo que se refiere a los intereses directos de las personas con discapacidad y no tanto de las entidades que decían representarles. Pero fue unos años más tarde (2001), cuando se radicalizó esta actividad política con la creación del FVID y el nuevo impulso que tomó la participación política directa de los sujetos concernidos.

Sin embargo, a pesar de toda esta militancia y de los notables avances en materia legislativa, los modelos tradicionales de la discapacidad todavía no han sido erradicados. En la práctica, el paradigma de la rehabilitación y el de la autonomía (o social, o de la diversidad funcional) conviven aún interrelacionados:

Los cambios de representación en el espacio legislativo no han llegado al espacio social, ni a los entornos educativo y laboral, ni a los espacios comunicativos e informacionales, culturales, artísticos, etc., ni muy especialmente, tampoco al espacio actitudinal (Toboso, 2013: 699)

Una convivencia que no está exenta de conflicto en el propio movimiento asociativo de la discapacidad ya que, como afirman Jiménez y Huete (2010), tanto los cambios legislativos como la emergencia de nuevos modelos asociativos han puesto en una encrucijada a las organizaciones de la discapacidad más tradicionales. 


\section{Las comisiones de diversidad funcional ${ }^{7}$}

Las acampadas del 15M irrumpen en un contexto de crisis económica, política y social en España, destapadas tras el colapso financiero del año 2008. Estas acampadas surgen a raíz de que diversas plataformas ${ }^{8}$ (constituidas mediante las redes sociales y al margen de partidos políticos, sindicatos y otras organizaciones tradicionales) convocan una manifestación unitaria el 15 de mayo del 2011 en toda España (Muñoz, 2011; Nez, 2012). A sólo una semana de elecciones (municipales y autonómicas) la manifestación reivindicaba una reforma de la ley electoral y la expulsión de imputados por corrupción de las listas electorales, junto con la defensa de los pilares básicos del Estado del Bienestar y un modelo económico sostenible y atento a las necesidades populares básicas (Requena, 2011; Haro y Sampedro, 2011). Miles de personas tomaron las calles ese día en cincuenta ciudades españolas y también en otros países ${ }^{9}$. Pero en Madrid, al finalizar la manifestación, un pequeño grupo decidió espontáneamente alargar la protesta acampando en la Puerta del Sol (Requena, 2011). Esta iniciativa atrajo la participación de un número creciente de personas en los días posteriores, replicándose además en otras ciudades españolas (Haro y Sampedro, 2011). Así, lo que empezó como una jornada de protestas acabó mutando hacia un movimiento de desobediencia civil constituido como una red de acampadas (Tejerina y Perugorría, 2012). Estas compartían un mismo modelo y cultura organizativa ${ }^{10}$, basada en la diversidad, la subjetividad, la transparencia, la confrontación abierta y orientada a la construcción del consenso y la "contaminación ideológica" por encima del dogmatismo (Romanos, 2011).

${ }^{7}$ La información que aquí se presenta sobre las comisiones de diversidad funcional está basada en las respuestas que desde ambas comisiones nos devolvieron a inicios del 2012, en base a un breve cuestionario enviado por correo electrónico. En ese cuestionario preguntábamos, con respuestas abiertas, sobre el origen, desarrollo y actividades llevadas a cabo, así como valoraciones individuales de algunas de las personas participantes. Esa información se fue complementando con el análisis de las actas de las reuniones de la comisión de diversidad funcional de Madrid correspondientes a la reuniones realizadas entre el 22 de mayo y el 29 de noviembre de 2011, públicamente accesibles en la web http://actasmadrid.tomalaplaza.net/?p=605, así como de la web de la comisión de Barcelona (http://diversitatfuncional15m.wordpress.com/). Las reflexiones posteriores también se complementan a partir de la propia experiencia en el desarrollo de las comisiones y/o las acampadas del 15M.

${ }^{8}$ Democracia Real Ya (DRY), Juventud sin Futuro, Plataforma de Coordinación de Grupos Pro-Movilización Ciudadana, Anonymous, No les Votes, Estado del Malestar, V de Vivienda, entre otros.

9 También se celebraron pequeñas manifestaciones en ciudades como Dublín, Ámsterdam, Estambul, Bolonia, París, Londres o Lisboa (Tejerina y Perugorría, 2012).

${ }^{10} \mathrm{La}$ asamblea general es el espacio de decisión, las comisiones y subcomisiones son para organizar y gestionar las actividades y los grupos de trabajo son para debatir sobre temas más concretos. 
Podemos decir que la democracia se consideraba un punto de llegada y no tanto de partida (Corsín, 2007). En consonancia, uno de los principios fundamentales fue el "no nos representan": un eslogan que además de servir para posicionarse contra las élites políticas y financieras, implicaba una apuesta por una democracia directa y con la deliberación en el centro de la acción y de la toma de decisiones, como alternativa al modelo de democracia representativa (Nez, 2012).

En el contexto de estas acampadas, las comisiones ${ }^{11}$ eran los espacios destinados al trabajo sobre temas específicos del movimiento, como por ejemplo, la economía, la política, el medio ambiente, el feminismo, la educación y la cultura, o las migraciones, entre otros. Siguiendo ese modelo organizativo, se creó una comisión de diversidad funcional tanto en la acampada de Madrid como en la de Barcelona ${ }^{12}$. Aunque en las comisiones participaron diversos grupos con una larga trayectoria y experiencia militante en el ámbito de la discapacidad, el FVID acabó teniendo un importante papel tanto por su posicionamiento crítico e independencia, como por los paralelismos con el modelo organizativo del $15 \mathrm{M}^{13}$. En ambos casos se cuestionaba la idea tradicional de representación política: el individuo tiene más importancia que el grupo y la representación se entiende siempre a título individual y organizada en forma de red (Gómez, 2012). De tal manera, que la lógica del "nada sobre nosotros, sin nosotros" del movimiento de vida independiente, acabó encontrando fácil acomodo en el marco del "no nos representan" del 15M.

El contexto de crisis epistemológico del sector de la discapacidad ${ }^{14}$, sumado a la reformulación económica, política y social que planteaba el $15 \mathrm{M}$, impulsó el objetivo de difundir el modelo social de la discapacidad y de derechos humanos ${ }^{15}$. Y ello de un modo que permitiera avanzar en el terreno legislativo, impregnando también el resto de organizaciones, espacios institucionales y en definitiva, el conjunto de la sociedad. Por este motivo, las comisiones dieron a conocer la Convención Internacional sobre los Derechos de las Personas con Discapacidad, visibilizando su incumplimiento y reivindicando un cambio social capaz de superar

${ }^{11}$ A pesar de que las diferencias entre denominarse "grupo" y "comisión" fue asunto de debate en algunas asambleas, creemos que esa cuestión sobrepasa los objetivos de este texto, en el que ambas palabras serán utilizadas como sinónimos.

${ }^{12}$ Mientras que en Madrid la comisión ha seguido funcionando desde entonces, la de Barcelona fue perdiendo constancia tras el levantamiento de la acampada en Plaza Catalunya en junio de 2011.

${ }^{13}$ Javier Romañanch, uno de los fundadores e ideólogos del FVID afirma que "el FVID fue un mini 15M diez años antes de aquel".

${ }^{14}$ Alimentado por la convivencia de modelos comprensivos de la discapacidad opuestos.

15 Una concepción que, en ocasiones, entraba en conflicto con el enfoque de la discapacidad (más cercano al modelo médico y asistencialista) sostenido desde otras comisiones del 15M, como la de educación o la de lo social. 
las contradicciones que presentaba la legislación española en este aspecto ${ }^{16}$. Este modelo de derechos humanos, además, se articulaba dentro de las alternativas a las medidas de austeridad ${ }^{17}$ adoptadas por el Estado, cuya crítica también estaba en la agenda del $15 \mathrm{M}^{18}$. Para ello llevaron a cabo numerosas actividades (debates, talleres, cine fórums, charlas, manifiestos, actividades lúdicas, intervenciones artísticas, etc.), en diferentes formatos (sensibilización, información, protesta, celebración, formación, reivindicación política, etc.), dirigidas a toda la ciudadanía $\mathrm{y}$ al resto de grupos de trabajo del $15 \mathrm{M}$.

Gracias a la permanencia en la plaza, las acampadas se convirtieron en sí mismas en un incentivo a la participación que acabó propiciando un lugar de encuentro para las "dos almas del movimiento": los ciudadanos a nivel individual y sin participación política previa, junto a personas activistas y militantes de diferentes movimientos con un largo recorrido político (Tejerina y Perugorría, 2012; Taibo, 2013). Las comisiones de diversidad funcional fueron el espacio que las personas con discapacidad construyeron para tomar la palabra y plantear su particularidad, visibilizándola y ubicándola en el espacio común. Desde la comisión de diversidad funcional de Madrid se afirma, por ejemplo: "Hemos asistido a muchas de las movilizaciones convocadas por el $15 \mathrm{M}$ juntos dando visibilidad y empoderamiento a las personas con diversidad funcional que participamos en el movimiento". Esto permitió abrir nuevas líneas de significación y discusión para dialogar sobre lo político de la discapacidad con personas que hasta ese momento no estaban familiarizadas con estas cuestiones, como afirma otra participante de la comisión de Madrid: "En las primeras semanas prefería escuchar y entender o aprender sobre los temas que se estaban tratando, alguno de ellos era la primera vez que los oía, eso me enganchó".

\footnotetext{
${ }^{16}$ Las reivindicaciones respecto al cambio legislativo en el marco de las comisiones de diversidad funcional giraban en torno a diversas cuestiones: la LEPA, la revisión del marco legal del aborto (en tanto biopolítica eugenésica), el modelo educativo (en tanto segregador) o la eliminación de las barreras (psicológicas, culturales, arquitectónicas, urbanísticas, de comunicación e información, etc.) que impiden la participación efectiva de las personas con discapacidad.

${ }^{17}$ Entre las actividades de las comisiones de diversidad funcional, encontramos también reivindicaciones como un aumento de las subvenciones destinadas a proyectos para personas con discapacidad, una gestión más eficaz de los recursos desarrollando modelos menos fragmentados de los servicios o una mayor inversión en acciones de investigación y sensibilización, entre otros.

${ }^{18}$ Según el Consejo Económico y Social de Naciones Unidas, las medidas de austeridad estarían perjudicando de forma desproporcionada al disfrute de sus derechos por las personas y los grupos desfavorecidos y marginados, especialmente los pobres, las mujeres, los niños, las personas con discapacidad, los adultos y los jóvenes desempleados, las personas mayores, los gitanos, los migrantes y los solicitantes de asilo (Consejo Económico y Social de Naciones Unidas, 2012: 3).
} 


\section{La común vulnerabilidad}

Más allá de hacer difusión de estas cuestiones vinculadas a la legislación y a los derechos humanos, las comisiones de diversidad funcional hicieron otro tipo de contribuciones mucho más significativos al marco del 15M. Las personas con discapacidad han sido un grupo oprimido y estigmatizado históricamente, en base a la idea de ser poseedores de una serie de rasgos fundamentalmente diferentes al resto, siendo la vulnerabilidad o la dependencia algunas de estas características asociadas (Beckett, 2006). Todos somos seres ontológicamente vulnerables e inseguros que vivimos en un entorno incierto, ante el cual no podemos responder mediante actos individuales y aislados (Turner, 2006), sin embargo, aspiramos a vivir en una "ficción de invulnerabilidad" (Nussbaum, 2006). Para sostener esta ficción, por un lado, tendemos a proyectar esta "vulnerabilidad" como rasgo exclusivo de determinados colectivos, maniobra mediante la cual son convertidos en "objetos de rechazo" (Nussbaum, 2006 y 2007); por el otro, creamos unas instituciones sociales inmunitarias, orientadas a perseguir y borrar esta vulnerabilidad intrínseca, desde un registro defensivo y de miedo a la diferencia (Esposito, 2009). Significa esto que la historia de persecución, discriminación y olvido que ha sufrido el colectivo evidencia que las personas con discapacidad encarnan un rechazo, casi ancestral, de la vulnerabilidad. Sin embargo, como resultado de las mejoras conseguidas en el ámbito de la discapacidad en los últimos años, junto con la emergencia de "nuevos riesgos sociales"19 ${ }^{19}$, la discapacidad habría ido perdiendo "el lugar preeminente que ocupaba en el ranking de la vulnerabilidad" (Jiménez y Huete, 2010: 150), planteándose la necesidad de crear otro tipo de alianzas políticas y apuntando hacia objetivos más transversales. Esta realidad, que se ha puesto especialmente de manifiesto con la actual crisis económica y social, muestra cómo la vulnerabilidad y dependencia asociada a "los otros" forman parte del día a día de una gran mayoría. Así, observamos que no existe la autosuficiencia y autonomía, sino únicamente continuidad entre los cuerpos (con y sin discapacidad). Y una vez reconocemos la vulnerabilidad como un rasgo intrínsecamente humano, ya no podemos aspirar a erradicarla sino únicamente a protegerla (Butler, 2004).

En este sentido, podemos destacar que uno de los elementos aglutinadores de la diversidad de perfiles que acogió el $15 \mathrm{M}$ fue precisamente cierta noción de precariado $^{20}$ (Standing, 2011, 2012). Esta crisis económica pone de manifiesto cómo el capitalismo global está imponiendo una creciente precarización de la

${ }^{19}$ Estos "riesgos" estarían asociados a "fenómenos como la transformación del rol de las mujeres y de los modelos familiares, las migraciones, el envejecimiento de la población o la reestructuración de los mercados laborales" (Jiménez y Huete, 2010: 150).

${ }^{20}$ Standing (2011) incluye a personas con discapacidad, mujeres, jóvenes, personas mayores, minorías étnicas y personas marginalizadas. 
existencia, ante la que cada vez más ciudadanos se sienten abandonados, ignorados y discriminados por el Estado. La noción de precariado surge de la conciencia de estar entre los principales afectados por esta precariedad vital generalizada, ante la que las políticas sectoriales se muestran ineficaces. Se plantea así la necesidad de desarrollar modelos alternativos más universalistas y al margen de procesos de categorización social, asumiendo que la vulnerabilidad es un rasgo esencialmente humano y transversal (Standing, 2011).

Por lo tanto, desde la noción de precariado y con la presencia de las comisiones de diversidad funcional en la plaza, se estaba cuestionando que la vulnerabilidad fuera un asunto que afectara solo a algunos grupos. Al contrario, esta nos equiparaba a todos como iguales. Así, era lógico revisar la idea de lo común en juego y, en consecuencia, lo que conllevaba la discapacidad en esta construcción de lo común. Si el objetivo del 15M era desarrollar una supuesta "revolución humana" era importante superar las luchas parciales, aun sin caer en las clásicas exclusiones de determinadas minorías. En el 15M, fueron esta experiencia de vulnerabilidad y fragilidad, junto con los conceptos de diversidad funcional y dependencia, las ideas fundamentales puestas en circulación. Es decir, la experiencia de la necesidad del otro y, con ella, la toma de conciencia que la dependencia, la fragilidad y la vulnerabilidad no son cuestiones referidas únicamente a esos otros, sino que conforman, justamente, el nosotros.

\section{El cuerpo y la plaza}

Fue importante que este proceso de construcción del nuevo "nosotros" se produjera en las acampadas, ya que obligaba a plantear todas estas cuestiones desde una experiencia de militancia encarnada. Como afirma Sutton (2007) la resistencia y protesta políticas no se basan únicamente en grandes ideas o visiones, sino que van siempre acompañadas de un intenso compromiso corporal: hay que "poner el cuerpo". Por un lado, en las protestas, el cuerpo funciona como base de las acciones (cantar, gritar, bloquear calles, enfrentarse a la policía, etc.) y como texto o argumento político en sí mismo (disfrazándose, maquillándose, llevando camisetas con slogans, etc.). Pero por otro lado, ese mismo cuerpo impone también sus propias limitaciones y necesidades (comer y beber, exponerse a las adversidades climáticas, ir al baño, descansar, etc.), que pueden variar en función del género, clase social u otras variables. Estas diferencias o particularidades a menudo han sido utilizadas para excluir a determinados cuerpos de los escenarios de protesta, por ser considerados más vulnerables y frágiles, especialmente en situaciones de riesgo (Sutton, 2007: 140 -142). Es en este sentido que fue y es tan importante el cuerpo en la plaza, y no cualquier cuerpo, sino este cuerpo marcado por una diferencia sustancial en relación al ideal cuerpo-capaz.

En el 15M se produjo cierta ambivalencia en este sentido, de modo que si por un lado se conseguía que, por ejemplo, tanto la acampada de Barcelona como la de Madrid fueran accesibles, también se cuestionó la idoneidad o no de determinados 
cuerpos para la protesta. A raíz de la agresión que recibió una persona en silla de ruedas durante una carga policial en la acampada de Barcelona, se abrió la controversia sobre su presencia en la plaza. La polémica generada fue tal que la persona agredida acabó emitiendo un comunicado reivindicando precisamente su derecho a manifestarse y a defenderse, y por lo tanto, su legitimidad para estar en la protesta, incluso en una situación como aquella ${ }^{21}$. Por lo tanto, el simple hecho de que las personas consideradas vulnerables ocupen el espacio público se convierte en una fuente de empoderamiento, al cambiar la imagen de sí mismas y de sus capacidades; haciendo de sus cuerpos no sólo portadores de mandatos opresivos, sino también fuerzas de liberación (Sutton, 2007: 156). Su presencia se convirtió en una prueba encarnada contra los estereotipos, cuestionando a su vez la imagen de lo que es un "activista” típico". De esta manera, el 15M ganó fuerza precisamente por dar acogida a la diversidad, no sólo ideológica y de identidades, sino también de cuerpos (diversidad funcional, pero también de sexo, género, edad, etnia, etc.). La importancia de poner el cuerpo en la plaza no la vemos como acto de ontología específica. Esto es: aquí pongo y muestro lo que yo soy, lo que es mi discapacidad en sí misma como esencia o sustancia, sino en la forma de esta exposición. En el caso que nos incumbe como cuerpo resistente desde la comunión que propició la precariedad y vulnerabilidad. Es decir, son los modos de ponernos en común lo que construyen el ser. No se actúa desde algo previamente constituido sino que es el hecho de estar colocados en común lo que funda, en formas diferentes, lo propio de cada uno. Quiere decir esto que modificar la manera en que uno se expone o se pone en común, modifica de facto su mismo ser (o la discapacidad, en el caso que nos incumbe). Son las formas de estar (o no estar) en común las que construyen la discapacidad en cuanto tal. En consecuencia, el significado de los cuerpos con diversidad funcional puede verse modificado a partir de otras formas de poner el cuerpo en lo común. Y justamente esto es lo que aconteció en la plaza (el cuerpo con diversidad funcional como resistente al ponerse en primera fila en las movilizaciones, como cuerpo golpeado por las fuerzas policiales, como cuerpo

${ }^{21}$ Ante el intento de desalojo-limpieza de la Plaza de Catalunya del 27 de mayo de 2011, las personas acampadas trataron de bloquear los camiones utilizando sus cuerpos como barrera para frenar a los camiones, hasta que los mossos empezaron a cargar contra la gente que estaba sentada pacíficamente en la calle (Toret, 2013: 112). Durante esas cargas resultó agredido Sebastián Ledesma, en silla de ruedas y miembro de la comisión de diversidad funcional. A raíz del debate generado tras la difusión de las imágenes, Sebastián respondió mediante un comunicado en el que reivindicaba, entre otras cosas, su legitimidad para estar en la plaza "como un indignado más", sin necesidad de ser considerado "ni un héroe, ni una víctima, ni un "borroka" ni, mucho menos un inconsciente", defendiendo que " todos somos iguales ante la ley y tenemos el mismo derecho de manifestación y de legítima defensa" (Ledesma, 2011). También puede verse un vídeo con ese comunicado en la web de la comisión (http://diversitatfuncional15m.wordpress.com/2011/07/14/comunicado-desebastian-ledesma/). 
alegre al celebrar su diversidad visiblemente, como cuerpo narrado y crítico al participar activamente en debates públicos...). Por tanto, poner el cuerpo en la plaza permitió hilvanar otras formas de estar en común. Permitió existir, porque existir es un ejercicio de exposición, un acontecer que sucede en el ponerse en común. Esta manera de comprender la existencia alude a un habitar (los espacios y el cuerpo) que produce la misma geografía. Eventualmente durante la ocupación de la plaza se produjo este nuevo modo de habitar los espacios y el cuerpo. Los manifestantes acampados (ex)pusieron sus cuerpos en común creando cierta conciencia de cuerpocomún. Como hemos visto, esto se alimentó con la creciente idea de precariedad/vulnerabilidad que estalló particularmente durante la ocupación. Sobre esto, son relevantes algunos testimonios que aluden a la sensación de haberse sentido confortablemente acompañados, durante esos días, en sus vidas precarias ${ }^{22}$. Así, la precariedad tomaba otras formas y generaba otros sentimientos al ponerla en común. Por tanto, exponer la vulnerabilidad estuvo directamente relacionado con un nuevo tipo de anudamiento social.

\section{Conclusiones}

Podemos entender el 15M como el prototipo de una nueva forma de participación que categorizamos como "participación por irrupción" ${ }^{23}$ y en un formato abierto que permitió la confluencia y alianza de personas que hasta ese momento habían luchado por separado o que, directamente, nunca antes habían estado movilizadas políticamente. Este espacio de intercambio permitió que se introdujeran en la agenda política nuevos debates, implicando a más personas y desde nuevas formas de acción.

En el caso de las comisiones de diversidad funcional, podemos decir que lo que venía ensayando el FVID, en su trayectoria de movilizaciones, se extendió y generalizó a un grupo más amplio de personas concernidas por el fenómeno de la discapacidad. A consecuencia del creciente proceso de precarización del conjunto de la población y a la propia crisis del sector de la discapacidad, se planteó la necesidad de construir nuevas alianzas políticas, de tal manera, que las mejoras que

\footnotetext{
${ }^{22}$ Testimonios recogidos durante observaciones realizadas en las acampadas del 15M${ }^{23}$ Según Martínez, los procesos de participación por irrupción o autónomos serían los protagonizados por parte de colectivos y organizaciones sociales que (sin la administración) intervienen espontáneamente en la esfera pública con sus reivindicaciones, propuestas y creación de proyectos colectivos. La participación por irrupción se contrapone en cierto modo a la participación por invitación. Es decir a aquella que utiliza mecanismos establecidos por la administración pública en cualquiera de sus niveles municipal, autonómico, estatal o supraestatal (2006: 6).
} 
se consiguieran para las personas con discapacidad estuvieran enmarcadas, también, en una mejora para el conjunto de la población (Jiménez y Huete, 2010: 150). El encuentro de las comisiones de diversidad funcional con las lógicas del 15M ha contribuido a producir un cambio y a concienciar sobre la necesidad de transformar los modos de hacer política del colectivo de personas con discapacidad. A saber, por ejemplo, extendiendo el uso político del cuerpo como arma de resistencia. Es decir, en las comisiones de diversidad funcional se observa otro punto de inflexión en los modos históricos de militar, caracterizado por un creciente uso político del cuerpo. Este uso se distingue de otros por la importancia política que toma aquí la vulnerabilidad y la lucha encarnada desde aquella.

Los debates y acontecimientos surgidos en la acampada dieron cuenta de un anudamiento social mediado por una nueva clase de precariado y sentimiento de fragilidad. Esta conciencia abrió un lugar para la diversidad funcional que alejó la vulnerabilidad de la ocultación o la vergüenza. A su vez, supuso también, la problematización de otros temas significativos. A saber, petición de mínimos vs cambio de fundamento social, luchas particulares vs intereses comunes, construcción de lo común sin exclusiones, entre otros.

Las comisiones de diversidad funcional ratificaron la conciencia general de vulnerabilidad y mostraron una nueva gestión política de esta. Hasta la fecha se había subrayado e insistido tanto en la autonomía y autosuficiencia que la dependencia se había convertido en una cuestión vergonzante. Lo señalado hasta aquí muestra la tendencia de regeneración y promoción de un nosotros distinto que recupera el alter y la conciencia de finitud y vulnerabilidad. Y esto, como decíamos, señala a su vez, nuevas formas de lucha encarnada y politización de los cuerpos.

En síntesis, el fenómeno de la discapacidad se ve alterado a la luz de la crisis y el cambio de paradigma. Toma una nueva significación y un nuevo rumbo en la conciencia de finitud y vulnerabilidad. El ser precario apunta al uso político del cuerpo como estrategia política de reivindicación. Desde aquí la discapacidad supone una inédita ontología del ser humano, no por nueva sino por olvidada y rechazada a golpe de violencia. Esta ontología está más relacionada con la apertura indefinida de lo que es el ser humano (como precario y dependiente) que con el cierre de lo que somos. La discapacidad supuso en las movilizaciones un símbolo de lo desterrado. Una posibilidad para comprender la realidad del ser humano que cambie el mismo modo de pensarse y pensar las diferencias y, con ello, modifique las relaciones que se establecen con el mundo y los otros. 


\section{Bibliografía}

Barnes, Colin, Mercer, Geof y Tom Shakespeare. 1999. Exploring Disability. A Sociological Introduction. Cambridge: Polity Press.

Beckett, Angharad E. 2006. Citizenship and Vulnerability. Disability and Issues of Social and Political Engagement. London: Palgrave Macmillan.

Butler, Judith. 2004. Precarious Life. The Powers of Mourning and Violence. London - New York: Verso.

Centeno Ortiz, Antonio. 2012. "Marco legislativo de la dependencia. Una visión crítica desde los derechos humanos", en Asun Pié, coord., Deconstruyendo la dependencia: propuestas para una vida independiente. Barcelona: UOC.

Clements, Luke y Jane Read. 2008. Disabled People and the Right to Life. New York: Routledge.

Consejo Económico y Social de Naciones Unidas. 2012. "Examen de los informes presentados por los Estados partes en virtud de los artículos 16 y 17 del Pacto Observaciones finales del Comité de Derechos Económicos, Sociales y Culturales, España", 6 de junio de 2012. Disponible en web: www2.ohchr.org/english/.../E.C.12.ESP.CO.5_sp.doc

Corsín Jiménez, Alberto. 2007. "Cooperación y procomún: relaciones antropológicas”, Archipiélago: cuadernos de crítica de la cultura, 77-78: 27-32.

Díaz Velázquez, Eduardo. 2008. "El asociacionismo en el ámbito de la discapacidad. Un análisis crítico", Intersticios, 2 (2): 183-195. Disponible en web: http://www.intersticios.es/article/view/2715/3127

Fierro, Alfredo. 1984. "España: Historia Reciente", en Richard C. Scheerenberger, Historia del Retraso Mental. San Sebastián: SIIS.

Esposito, Roberto . 2009. Comunidad, inmunidad y biopolítica. Barcelona: Herder.

Ferreira, Miguel A.V. 2010. "De la minus-valía a la diversidad funcional: un nuevo marco teóricometodológico”, Política y Sociedad, 47 (1): 45-65. Disponible en web: http://revistas.ucm.es/index.php/POSO/article/view/22816

Gómez Jiménez, Núria. 2012. "Vida independiente: instrumentos para garantizar el cambio de paradigma", en Asun Pié, coord., Deconstruyendo la dependencia: propuestas para una vida independiente. Barcelona: UOC.

Haro Barba, Carmen y Víctor Sampedro Blanco. 2011. "Activismo político en Red: del Movimiento por la Vivienda Digna al 15M", Revista Teknocultura, 8 (2): 167-185. Disponible en web: http://teknokultura.net/index.php/tk/article/view/14

Jiménez Lara, Antonio y Agustín Huete García. 2010. "Políticas públicas sobre discapacidad en España. Hacia una perspectiva basada en los derechos", Política y Sociedad, 47 (1): 137 - 152. Disponible en web: http://revistas.ucm.es/index.php/POSO/article/view/22848/0

Ledesma, Sebastián. 2011. "Testimoni del lector", en La Vanguardia, 1 de junio de 2011. Disponible en web:

http://www.lavanguardia.com/participacion/20110601/54164400665/elsmossos-d-esquadra-van-agredir-me.html 
Maraña, Juan José y Manuel Lobato. 2003. "El movimiento de Vida Independiente en España", en Jordi Vidal García Alonso, coord., El movimiento de Vida Independiente. Experiencias Internacionales. Madrid: Fundación Luis Vives. Disponible en web: http://sid.usal.es/libros/discapacidad/6418/8-1/revistaenlace.aspx

Martínez, Zesar. 2006. "Globalización política y crisis democrática; retos para las ciencias sociales desde una perspectiva educativa", en Propuestas para otra globalización. Relatorías de los seminarios, octubre 2005 - febrero 2006. Instituto de Estudios sobre el desarrollo y Cooperación, Universidad del País Vasco. Disponible en web: http://www.hegoa.ehu.es/congreso/bilbo/cas/Relatoriagrupo3def.pdf

Mitra, Sophie. 2006. "The Capability Approach and Disability", Journal of Disability Policy Studies, $16 \quad$ (4): $236 \quad-247 . \quad$ DOI: 10.1177/10442073060160040501

Muñoz, Alba. 2011. "Del síndrome Wikileaks a la democracia 2.0. Las redes sociales y el 15-M", en VVAA, Las voces del 15-M. Barcelona: Los libros del Lince. Disponible en web: http://archive.org/details/LasOcesDel15m

Nez, Héloïse. 2012. "Entre los militantes y los laboratorios deliberativos: el 15-M", en Benjamín Tejerina e Ignacia Perugorría, eds., From Social to Political. New Forms of Mobilization and Democratization. Conference Proceedings. Bilbao: Universidad del País Vasco. Disponible en web: http://identidadcolectiva.es/index.php?option=com_content\&view=article\&id=3 $26:$ \& catid $=28:$ simposia\&Itemid $=48$

Nussbaum, Martha C. 2006. El ocultamiento de lo humano. Repugnancia, vergüenza y ley. Buenos Aires: Katz Editores.

-----.2007. Las fronteras de la justicia. Consideraciones sobre la exclusión. Barcelona: Paidós.

Palacios Rizzo, Agustina y Javier Romañach Cabrero. 2006. El modelo de la diversidad. La Bioética y los Derechos Humanos como herramientas para alcanzar la plena dignidad en la diversidad funcional. Santiago de Compostela: Diversitas Ediciones.

Palacios Rizzo, Agustina y Francisco José Bariffi. 2007. La discapacidad como una cuestión de derechos humanos. Una aproximación a la Convención Internacional sobre los Derechos de las Personas con Discapacidad. Madrid: Cinca.

Pérez, E. 1992. "Radiografía de un cuento de nunca acabar”, en Antoni Vilà, ed., Crónica de una lucha por la igualdad. Barcelona: Institut Guttmann.

Planella, Jordi y Asun Pié. 2012. Militancia y diversidad funcional. Barcelona: UOC.

Pié, Asun, coord., 2012. Deconstruyendo la dependencia: propuestas para una vida independiente. Barcelona: UOC.

Requena Aguilar, Ana. 2011. "Una crónica del 15-M", en VVAA, Las voces del 15$M$. Barcelona: Los libros del Lince. Disponible en web: http://archive.org/details/LasOcesDel15m 
Romanos, Eduardo. 2011. "El 15M y la democracia de los movimientos sociales", La Vie des Ideés. 18 de noviembre de 2011. Disponible en web: http://www.booksandideas.net/El-15M-y-la-democracia-de-los.html

Romañach, Javier y Manuel Lobato. 2005. Diversidad Funcional, nuevo término para la lucha por la dignidad en la diversidad del ser humano. Madrid: Foro de Vida Independiente. Disponible en web: http://www.forovidaindependiente.org/node/45

Taibo, Carlos. 2013."The Spanish indignados: A movement with two souls", European Urban and Regional Studies, 20 (1): 155- 158.

Tejerina, Benjamín e Ignacia Perugorría. 2012. "Continuities and Discontinuities in Recent Social Mobilizations. From New Social Movements to the Alter-Global Mobilizations and the 15M", en Benjamín Tejerina e Ignacia Perugorría, eds., From Social to Political. New Forms of Mobilization and Democratization. Conference Proceedings. Bilbao: Universidad del País Vasco. Disponible en web:

http://identidadcolectiva.es/index.php?option=com_content\&view=article\&id=3 26: s\&catid=28: simposia\&Itemid $=48$

Toboso Martín, Mario. 2013. "De los discursos actuales sobre la discapacidad en

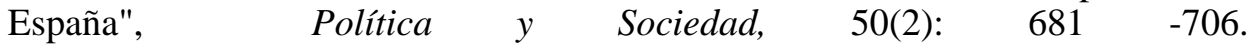
http://dx.doi.org/10.5209/rev_POSO.2013.v50.n2.39007

Toret, Javier, coord., 2013. Tecnopolítica: la potencia de las multitudes conectadas. El sistema red 15M, un nuevo paradigma de la política distribuida. Barcelona: Internet Interdisciplinary Institute (IN3) - Universitat Oberta de Catalunya (UOC). Disponible en web: http://journals.uoc.edu/ojs/index.php/in3-workingpaper-series/article/view/1878

Turner, Bryan S. 2006. Vulnerability and Human Rights. Pennsylvania: The Pennsylvania State University.

StANDing, GuY. 2011. THE PRECARIAT: THE NEW DANGEROUS ClASS. LONDON: BLOOMSBURY ACADEMIC. EN LÍNEA EN: DOI: 10.5040/9781849664554

----- 2012. “The Precariat: From Denizens to Citizens?” Polity, 44 (4): 588608. DOI:10.1057/POL.2012.15.

Sutton, Bárbara. 2007. "Poner el Cuerpo: Women's Embodiment and Political Resistance in Argentina". Latin American Politics and Society, 49 (3): 129 -162. DOI: 10.1111/j.1548-2456.2007.tb00385.x 